\title{
Research to Wearing Comfort for Women's Jeans Based on Factor Analysis Method
}

\author{
Min Dong, Huimin Xiang and Xiangpeng $\mathrm{Li}^{*}$ \\ Wuhan Textile University, 430073 Wuhan, China \\ ${ }^{*}$ Corresponding author
}

\begin{abstract}
Nowadays people have a higher demand for wearing comfort on jeans, but there are few researches related to the impact factors of wearing comfort on women's jeans. Considering the needs of the market, we studied the impact factors of wearing comfort on women's jeans in this paper. On the basis of literature reviews and survey to the consumers, we selected 21 key impact indices related to wearing comfort on women's jeans, and then collected a total of 252 sample data from a group of 18-25 young women through questionnaire survey. After reliability, validity, single dimension of questionnaire were tested, we extracted four main common factors such as material, structure of jeans, technology, and external environment. Among four common factors, the relative impact of material and structure are greatest. According to these impact factors, jeans production enterprises can adjust corresponding technology and improve products so as to obtain the maximum market profit.
\end{abstract}

Keyword-women's jeans; wearing comfort; impact indices; factor analysis; single dimension examination; validity examination

\section{INTRODUCTION}

With the development of economy and the improvement of living level, people's requirement to clothes quality is higher. They more and more pay attention to the garment comfort besides beauty and pursue optional, free, light, comfortable and fitting. Therefore, each part of clothes has to make people comfortable and adapts the demand of static and dynamic function. It is necessary to realize the change from "know clothing" to "Clothing serves people".

Comfort is a complex concept and it covers many details. Human is the first key factor. In the system of human-clothing-environment [1], human is the subject because he or she is the wearer and percipient of environment. The wearing comfort is the feeling of human on physiology and psychology. Clothing is the second key factor. Many indices have an important effect on comfort such as the material, style, modelling, construction, size, pressure, weight, and so on. Nature environment is also a key factor including season, temperature, humidity, and so on. Therefore, garment comfort is a comprehensive concept and it is harmony and unity of human, clothing and environment. These indices are not isolated but interconnected and interactional organism. We can take full advantage of them to improve the garment comfort for serving people if all impact factors can be analyzed.

Pants pay an important role in women's dress. Not only does it covers lower body, but also has to be convenient for daily activities of lower body. Only the pants are comfortable according with characters of lower body shape and activity rules. The cowboy culture has been popular for many years, and women are the important part of jeans consumer groups. At present, jeans are the most popular pants in young consumers. The diversified requirement of young women to jeans makes comfort emphasized further instead of durability. At present, in consumption market less jeans brands can compete with big international brand such as Levi's, Lee, CK, and so on. An important reason is that they more focus on wearing comfort besides aesthetics.

The research on garment comfort begins in twenty century, and researchers have done a good deal of work [2]-[7]. But they mainly pay attention to pressure comfort or one side feature of clothing according to technical knowledge such as thermodynamics and physiology while the researches based on consumers' mentality are less done. We know that clothing serves human, so we have to focus on consumers' feeling. Both of consumption customs and personal preferences are different and extremely subjective, therefore, it is necessary to finish physiological evaluation with the help of garment ergonomics. It means that we need identify the evaluation indices on wearing comfort and classify them appropriately. In this paper, we will visit consumers and further research the impact factors related to wearing comfort on women's jeans by using factor analysis method for satisfying the demand of market.

\section{FACTOR ANALYSIS METHOD}

Factor Analysis is a multivariate statistical method by which variables with complex relation are summed up to several comprehensive factors. The basic idea is to divide variables with high relevancy into a class, which is called as common factor, while the relevancy is lower between different classes. The purpose is to describe each initial observational variable by using the sum of linear function of common factor and special factor.

\section{DESIGN OF QUESTIONNAIRE}

In this paper, research data is from visiting and questionnaire based on sensory evaluation. 300 young women with different age and education level take part in evaluation on the impact degree of each comfort factor and the number of effective questionnaires is 252. The evaluation scores are from a set of five levels \{very unimportant (1), unimportant (2), neural (3), important (4), very important (5)\} and participants will select a score from $\{1,2,3,4,5\}$ for each question.

\section{A. Identification of Impact Indices}

Based on literature research [5]-[10], 25 possible impact indices on dressed comfort are extracted such as Season, Temperature, Air Permeability, Hygroscopicity, Humidity, Warmth, Thickness, Softness, Hardness, Smoothness, 
Flexibility, Pressure, Washing, Style and Pattern, Waist Height, Waist Girth, Hip Girth, Crotch Depth, Leg Opening, Fitness, Pants Length, Hip Length, Total Crotch Width, Stitches and Vertical Incline Angle of in-leg, Zipper. According to visiting designers and consumers, some unsuitable factors are deleted such as Pants Length, Hip Length, Total Crotch Width, Stitches and Vertical Incline Angle of in-leg. Ultimately, 21 impact indices are identified.

\section{B. Reliability Analysis to Questionnaire}

Reliability analysis is to analyze the stability and consistency of research problems. Generally, the higher stability and consistency degrees are, the higher the reliability of analysis to details is. On contrary, the reliability is lower. Reliability is divided into two classes including external reliability and internal reliability. External reliability means there is rather higher consistency among survey results obtained at different time. Our research is not very related to time, therefore, external reliability will be considered in this paper. Internal reliability means that all questions have internal consistency and they can express the same concept. The value of "Cronbach Alpha" can be used to examine the consistency between questions in single dimension. In our research, the whole reliability of this questionnaire and the reliabilities of 21 comfort indices are examined respectively and listed in Table I and Table II.

TABLE I. THE WHOLE RELIABILITY OF QUESTIONNAIRE

\begin{tabular}{ccc} 
Cronbach's Alpha & Standardized Cronbach's Alpha & Option number \\
\hline 0.893 & 0.884 & 24 \\
\hline
\end{tabular}

TABLE II. THE RELIABILITY OF 21 FACTORS

Cronbach's Alpha Standardized Cronbach's Alpha Option number
0.909 0.912 21

According to TABLE I and TABLE II, it is known that the "Cronbach Alpha" coefficient of the questionnaire and all factors are all more than 0.7 , which means consistency of this questionnaire and its test factors are rather higher. Therefore, this questionnaire passes reliability examination and can be rather analyzed.

\section{FACTOR ANALYSIS TO WEARING COMFORT INDICES}

In past, people usually selected more indices to describe real world by way of multivariate analysis. However, too many indices will add the complexity of research and even lead to chaos because of the dependency between indices. Therefore, researchers often apply factor analysis method to simplify index numbers on the basis of remaining information integrity. Those variables with high relation degree will be classified to a set and each set can be expressed by a factor. In this paper, we will find out several common factors to describe the relation between 21 indices.

\section{A. KMO and Bartlett Examination}

KMO (Kaiser-Meyer-Olkin) samples measure and Bartlett spherical examination are used to determine if data is fit for factor analysis. Generally speaking, for factor analysis, it is extremely suitable if the value of KMO is more than 0.9 and the closer to 1 the value is, the higher the adaptability is; it is suitable if the value of KMO is more than 0.8 and less than 0.9 ; it is basically suitable if the value of KMO is more than 0.7 and less than 0.8; it is not suitable if the value of KMO is less than 0.7. In addition, in Bartlett spherical examination, the explanation ability is more prominent when the value of "sig." is smaller. The examination results are shown in Table III.

According to Table III, it is suitable for the questionnaire to use factor analysis method.

TABLE III. KMO AND BARTLETT EXAMINATION

\begin{tabular}{cccl}
\hline $\begin{array}{c}\text { KMO } \\
\text { measurement }\end{array}$ & \multicolumn{3}{c}{ Bartlett spherical examination } \\
Approximate Chi-square & df & Sig. \\
\hline .824 & 4675.725 & 210 & 0.000 \\
\hline
\end{tabular}

\section{B. Exploratory Factor Analysis to Indices}

We extract 4 common factors from 21 measurement indices as Table IV.

TABLE IV. RELATED IMPACT INDICES AND CLASSIFICATION

\begin{tabular}{cccc}
\hline Material & Construction & Technology & Environment \\
\hline Air Permeability & Waist Height & Style and & Temperature \\
Hygroscopicity & Waist Girth & Pattern & Humidity \\
Softness & Hip Girth & Washing & Season \\
Hardness & Crotch Depth & Zipper & \\
Smoothness & Leg Opening & & \\
Thickness & Fitness & & \\
Flexibility & & \\
Pressure & & \\
Warmth & & \\
\hline
\end{tabular}

We have to analyze whether the 21 indices can be covered in common factors by basic statistics and the results are shown in Table V.

TABLE V. DESCRIPTION STATISTICS

\begin{tabular}{cccccc}
\hline Index & Mean & $\begin{array}{c}\text { Standard } \\
\text { Deviation }\end{array}$ & Index & Mean & $\begin{array}{c}\text { Standard } \\
\text { Deviation }\end{array}$ \\
\hline Thickness & 4.12 & 0.971 & Waist Height & 4.07 & 1.091 \\
Flexibility & 4.12 & 0.983 & Waist Girth & 3.49 & 1.172 \\
Washing & 4.01 & 1.120 & Hip Girth & 3.61 & 1.147 \\
Warmth & 4.07 & 0.975 & Crotch & 3.50 & 1.172 \\
Softness & 4.25 & 0.900 & Depth & 3.26 & 1.105 \\
Hardness & 4.18 & 0.942 & Leg Opening & 3.55 & 1.269 \\
Smoothness & 3.85 & 1.077 & Fitness & 4.05 & 1.036 \\
Air Permeability & 4.13 & 0.938 & Style and & 4.10 & 1.067 \\
Hygroscopicity & 4.26 & 0.862 & Pattern & 3.90 & 1.067 \\
Pressure & 4.02 & 1.002 & Temperature & 4.07 & 1.046 \\
Zipper & 4.08 & 1.169 & Humidity & & \\
& & \multicolumn{5}{c}{ Season } \\
\hline
\end{tabular}

Obviously, the mean of each item is more than 3, which indicates that all participants keep positive attitudes to the importance of extracted 21 indices. Therefore, they can be covered in common factors.

The rotated load values of factors are listed in Table VI (It is shown in the next page). From Table VI, it is known that the interpretation degree of four extracted factors equals to $72.73 \%$ on total variable, which is more than $60 \%$. Therefore, four factors have a better interpretation to the questionnaire. 
The total variance of interpretation is shown in Table VII (It is shown in the last page).

In addition, the result is not ideal if the initial 25 indices are analyzed by factor analysis. The total variance of interpretation of initial indices is listed in Table VIII (It is shown in the last page) and four delated indices cannot be classified to any common factor.

TABLE VI. ROTATED COMPONENT MATRIX

\begin{tabular}{|c|c|c|c|c|c|}
\hline \multirow{2}{*}{ Index } & \multicolumn{4}{|c|}{ component } & \multirow{2}{*}{$\begin{array}{c}\text { interpretation } \\
\text { value of } \\
\text { variance } \\
\end{array}$} \\
\hline & 1 & 2 & 3 & 4 & \\
\hline Flexibility & 0.860 & & & & \\
\hline Softness & 0.846 & & & & \\
\hline Air Permeability & 0.845 & & & & \\
\hline Hygroscopicity & 0.841 & & & & \\
\hline Thickness & 0.835 & & & & 0.68 \\
\hline Warmth & 0.814 & & & & \\
\hline Hardness & 0.803 & & & & \\
\hline Smoothness & 0.801 & & & & \\
\hline Pressure & 0.799 & & & & \\
\hline Fitness & & 0.883 & & & \\
\hline Hip Girth & & 0.863 & & & \\
\hline Crotch Depth & & 0.853 & & & 0.675 \\
\hline Waist Girth & & 0.845 & & & \\
\hline Leg Opening & & 0.843 & & & \\
\hline Waist Height & & 0.609 & & & \\
\hline Temperature & & & 0.894 & & \\
\hline Season & & & 0.891 & & 0.695 \\
\hline Humidity & & & 0.702 & & \\
\hline Washing & & & & 0.867 & \\
\hline Style and Pattern & & & & 0.833 & 0.598 \\
\hline Zipper & & & & 0.590 & \\
\hline
\end{tabular}

We know that the interpretation degree of factors is reduced to $68.997 \%$ from $72.726 \%$. And there are not close relationship between these four indices and other indices. Based on visiting to consumers once again, we know the reason is that these four indices cannot be comprehended by ordinary consumers.

\section{Examination of Single Dimension and Construct Validity}

\section{1) Examination of single dimension property}

Single dimension means that only single character or construct can be regarded as representative in a group of measurement factors. Generally speaking, it can be considered from two aspects.

a) Each measurement factor is dramatically related to correspondent potential variables.

b) Each measurement factor is only associated with unique correspondent potential variable.

From TABLE VI, the loads of rotated 21 indices are more than 0.5 and it indicates the correlation is rather higher between 21 indices and four common factors; therefore, it satisfies the first condition of single dimension.

The second condition can be tested by the interpretation value of variance. It is known that these measurement indices have higher representativeness on common factors if the interpretation value of variance of a common factor is more than 50\%. At the moment, the second condition will be satisfied. The interpretation value $w$ of variance is defined as formula (1).

$$
w=\frac{1}{n} \sum_{i=1}^{n} c_{i}^{2}
$$

where $n$ is the number of measurement indices; $c_{1}, c_{2}, \ldots, c_{n}$ are respectively the load values of each rotated measurement index. The results are shown in Table VI.

According to the results, the interpretation values of variance of four common factors go over 50\%. the interpretation value of variance. It makes clear that the single dimension property of questionnaire is very good.

\section{2) Examination of construct validity}

Validity is defined as the degree of examined indices can be tested, i.e. the consistency between experiment and theory. It means if an experiment can indeed test the hypothesis theory and shows the relationship between construct variance and its measurement indices. According to TABLE VI, it is known that the factor loads of 21 measurement indices are all over 0.5 and there is not cross load in all factors. Therefore, we can determine that four common factors have better validity.

\section{The Interpretation to Common Factors}

\section{1) Material factor}

Material is a key factor related to tactile comfort. By factor analysis, it covers Air Permeability, Hygroscopicity, Softness, Hardness, Smoothness, Thickness, Flexibility, Pressure, and Warmth. These are just concerned by women consumers when they selected the fabric of jeans.

\section{2) Construction factor}

Construction is a key factor related to static and dynamic comfort when a woman wears jeans including Waist Height, Waist Girth, Hip Girth, Crotch Depth, Leg Opening and Fitness. It reflects the fitting requirement of consumers on each part of jeans.

\section{3) Technology factor}

Technology is an important factor related to appearance and practicability when wearing jeans. It mainly covers Style and Pattern, Washing and Zipper. For consumers, appearance and practicability are still taken as the most important factors though the driving factors are diversified and personalized on technology of jeans.

\section{4) Environment factor}

The dress feeling is different with the change of external environment. The heat exchange is realized between human and environment through conduction and convection. The impact is mainly come from change of Temperature, Humidity and Season. There is temperature difference between human and environment, and human body will generate heat when temperature is rather higher, therefore, people will feel uncomfortable with thick and heavy clothes while light and thin ones will be popular. The clothes will be sticky to human 
body if the humidity is too high; on contrary, people will feel dry if humidity is too lower and it is easy to generate static electricity.

\section{CONCLUSION}

On the basis of the former research, this paper chooses 252 young women as questionnaire objects, and conducts descriptive statistical analysis, reliability analysis, validity analysis and single dimension analysis for questionnaire. From the analysis results, it is shown that the questionnaire is fit for analyzing by factor analysis method. According these convey data, 21 inner influencing indices are analyzed deeply by exploratory factor analysis and ultimately four common factors are obtained including material, construction, technology and environment. Analysis results show that four factors can better explain the questionnaire. According to further analysis, the material factor and construction factor are two most key factors. For material factor, flexibility, softness and air permeability are more concerned. For construction of jeans, the more important indices are fitness, hip girth and crotch depth. In addition, two pre-designed factors including aesthetics and thermal-wet comfort are transformed into technology factor and material factor.

With the improvement of people's living demand and the further spreading of jeans culture, jeans market especially women's jeans market will still go on developing. Comfortable clothes can not only bring people nice body feeling, but also improve their living quality. According the study, majority young women think that comfortable jeans are extremely relevant to fine material quality and suitable pattern. Therefore, producers can improve corresponding technology and adjust the combination of products.

\section{ACKNOWLEDGMENT}

The paper is supported by Hubei Province Education Department Project Q20141603 in China and Science \& Technology Guidance Project 2015081 of China National Textile and Apparel Council.

\section{REFERENCE}

[1] Jianxing ZHANG, Costume Designing Ergonomics. CA: Light industry of China Press, 2010.

[2] Xiaoxia SONG, Xunwei Feng, "The relationship between clothing pressure and human comfort”, Journal of textile research, vol. 27, pp. 18-27, 2006.

[3] Lina LU, "The factor analysis of evaluation indices on nightclothes fabrics comfort performance”, Journal of Xi An Polytechnic University, vol 23, pp. 59-64, 2009.

[4] Jizuo WU, Gengxin Liu, "The research on the influencing factors of women's pants construction”, Tianjin textile science and technology, pp. 44-49, 2010.

[5] Liying LIU, Lin LIU, "Subjective evaluation of clothing comfort and their correlation with laboratory test", Journal of Qingdao University (Engineering \& Technology Edition), vol. 28,pp. 60-63, 2013.

[6] Zhongqi ZHANG, "Evaluation of jeans wear comfortability in differentwaist position”, Journal of Xi An Polytechnic University, vol. 24, pp. 165-171, 2010.

[7] Xiuyan ZHANG, "Fuzzy cluster Analysis Application in clothing Comfortability Evaluation", Journal of beijing institute of clothing technology (natural science edition), vol. 21,pp. 69-72, 2001.

[8] Volino, P., "From measured physical parameters to the haptic feeling of fabric", The Visual Computer, vol. 23, pp. 133-145, 2007.

[9] Jie Lu, "A linguistic multi-criteria group decision support system for fabric hand evaluation”, Fuzzy Optim Decis Making, vol. 8, pp. 395-413, 2009.

[10] ]Ying ZHANG, Haifeng XIAO, "The Characteristics, Structure and Trend of the Chinese Urban and Rural Residents' Clothing Consumption”, Asian Agricultural Research, pp. 34-47, 2014.

TABLE VII. TOTAL VARIANCE OF INTERPRETATION

\begin{tabular}{ccccccc}
\hline & \multicolumn{3}{c}{ Initial eigenvalue } & \multicolumn{3}{c}{ Rotated quadratic sum } \\
\cline { 2 - 6 } component & Total & $\begin{array}{c}\text { percent } \\
\text { variance(\%) }\end{array}$ & $\begin{array}{c}\text { cumulative } \\
\text { percent } \\
\text { variance(\%) }\end{array}$ & Total & $\begin{array}{c}\text { percent } \\
\text { variance(\%) }\end{array}$ & $\begin{array}{c}\text { cumulative } \\
\text { percent } \\
\text { variance(\%) }\end{array}$ \\
\hline 1 & 8.003 & 38.108 & 38.108 & 6.400 & 30.479 & 30.479 \\
2 & 3.759 & 17.902 & 56.010 & 4.410 & 20.998 & 51.476 \\
3 & 1.848 & 8.801 & 64.812 & 2.326 & 11.079 & 62.555 \\
4 & 1.662 & 7.915 & 72.726 & 2.136 & 10.171 & 72.726 \\
\hline
\end{tabular}

TABLE VIII. TOTAL VARIANCE OF INTERPRETATION AFTER INITIAL FACTORS ADDED

\begin{tabular}{ccccccc}
\hline \multirow{2}{*}{ component } & \multicolumn{2}{c}{ Initial eigenvalue } & \multicolumn{2}{c}{ Rotated quadratic sum } \\
\cline { 2 - 6 } & Total & $\begin{array}{c}\text { percent } \\
\text { variance(\%) }\end{array}$ & $\begin{array}{c}\text { cumulative percent } \\
\text { variance(\%) }\end{array}$ & Total & $\begin{array}{c}\text { percent } \\
\text { variance(\%) }\end{array}$ & $\begin{array}{c}\text { cumulative percent } \\
\text { variance(\%) }\end{array}$ \\
\hline 1 & 8.863 & 35.451 & 35.451 & 6.563 & 26.251 & 26.251 \\
2 & 4.303 & 17.213 & 52.664 & 4.654 & 18.615 & 44.867 \\
3 & 2.266 & 9.064 & 61.728 & 3.689 & 14.756 & 59.623 \\
4 & 1.817 & 7.269 & 68.997 & 2.343 & 9.374 & 68.997 \\
\hline
\end{tabular}

